\title{
Cost and Value: Based on the "Theory of Practice" Design Criticism Behavior
}

\author{
Wang xiaodong ${ }^{1,2, *}$ \\ ${ }^{1}$ Academy of Fine Arts, Sichuan Normal University, Chengdu, Sichuan, China \\ ${ }^{2}$ Academy of Fine Arts, Shaanxi Normal University, Xi'an, Shaanxi, China \\ *Corresponding author. Email: wxd-1230@163.com
}

\begin{abstract}
The existence of anything has its two sides, and design not only pays a price but also creates value. In order to achieve the maximum effect of value, it is necessary to carry out deep reflection and criticism in the practical experience. The article takes design practice as the ontology. Through a single comparative analysis of thinking and existence, practice and reflection in the design practice ontology, combined with the architectural ideas and methods of famous architects, on the basis of inheriting the design ideas of the predecessors, it is clearly proposed Practice as a means and practice with the purpose of creating value must adhere to the basic principles of practice and reflection, be guided by the concept of sustainable development, and then discover the truth through practice.
\end{abstract}

Keywords: design, practice, reflection, criticism

\section{代价与价值：基于 “实践论” 的设计行为批判}

王小冬 ${ }^{1,2, *}$

\author{
1 四川师范大学美术学院, 成都, 四川, 中国 \\ 2 陕西师范大学美术学院, 西安, 陕西, 中国 \\ wxd-1230@163.com
}

\section{中文摘要}

任何事物的存在均具有其两面性，设计在创造价值的同时也付出了相应的代价。为了达到价值最大化 效果, 就需要在实践的体验中进行深刻反思批判。文章以设计实践为本体, 通过对设计实践本体中的 思维与存在、实践与反思的比较分析, 结合著名建筑师的建筑思想和方式方法, 在继承前辈设计思想 的基础上，明确提出以设计实践为手段，以创造价值为目的的实践行为，必须坚持实践与反思的基本 原则，以可持续发展观为导向，进而通过实践发现真理。

关键词: 设计; 实践; 反思; 批判

\section{1. 引言}

“道可道, 非常道”, 每一个人论道的方式和起 点都不同, 这源于每一位论道者所处的环境和心性。 造物有其规律, 这规律有一些可认知、可讲, 有一些 正在认知, 还有一些可以认知却无法阐释。 ${ }^{[1]}$ 但是我 认为我们今天所谈的 “设计” 还是有别于传统的造物, 它的主动性、自觉性以及所处环境的复杂性与矛盾性 大大超过了传统的造物。除了实用, 今天的设计更强 调它的社会和文化意义。设计中的创造性就是指设计 者面对沉重和复杂问题所显现出来的智慧。这种人类
神性的觉醒并表现为智慧的东西就是 “道”。 ${ }^{[2]}$ 基于 “实践论” 的设计反思之道并不是自己所创, 而是在 大量设计实践中的所思与所悟。由于当代社会发展迅 速, 大量设计实践较好地服务于大众和上层建筑，反 观之, 能够清楚地发现设计创造价值的同时也付出了 沉重的代价。基于此, 从历史和哲学范畴寻求设计理 论支撑就尤为迫切。

\section{2. 设计实践本体}

亚里斯多德认为, 实践知识与理论知识的不同处 
在于后者是人类以理性功能中的最高的直观理性来面 对不可改变的和永恒的存在; 而前者则是人类在面对 可改变之存在时, 以 “实用智慧” 来探索实践性的问 题。近代哲学中, 康德虽将认知与实践的理性功能予 以划分, 但是更强调实践理性的优越功能; 这种实践 理性并不是属于技术层次的实践问题, 而是诉诸于自 由意志的真正实践。后来德国观念论认为实践是一种 历史的过程, 如黑格尔强调由实践形成社会的功能, 而马克思则认为实践是社会的产物, 是 “理论” 与 “实际”的综合, 也是人类本质的展现。辩证唯物主 义者则进一步认为, 社会实践是所有知识的真理基准。 存在主义者则认为实践是一种人类所独具的行为模式, 如德国存在主义哲学家雅斯贝尔斯所认为的实践是使 人完成人所以为人的存在。

任何理论与学术新知均是由人创造和建立, 设计 理论也是如此。因学人的文化背景与思想前提的不同, 设计思维方式也存在较大差异。在相同理论的指导下， 最终的设计实践结果截然不同。存在这种差异的问题 不仅仅是文化背景和思维前提的不同, 更大的差异在 于设计观的不同。不同的设计观直接影响到设计思维 模式的建构和设计思维指导下的设计实践行为。在实 践过程中既存在着统一, 又存在着矛盾。如何处理统 一与矛盾的关系问题, 必须要有哲学思考与判断。尽 管哲学是追求终极统一的学问, 几乎所有哲学家对哲 学是什么, 反思的前提和意义等的理解也有所不同。

设计是人类重要的造物实践活动之一, 古往今来 皆有之。设计实践, 同样需要有理论指导, 规范设计 行为, 进而形成设计结果, 更好地为人类社会发展和 进步服务。作为设计从业者和教师, 更应该有科学的 设计观, 以及作为设计观支撑模型的思维模式, 乃至 思维体系。根据多年的设计实验经历与体验, 笔者认 为在形成自我设计思维模式之前, 需要将思维与存在, 实践与反思, 科学发展观作为其反思的前提而存在。 否则, 在创造价值的同时将付出沉重的代价, 众多粗 制滥造项目已被屡次证实如是也。

\section{3. 思维与存在}

人具有高度思维能力和创造性动能。因知识背景、 实践经历与体验深度相异, 思维方式存在的状态则有 所不同，故而影响到指导实践的路径与方法有所差异， 导致最终的结果截然不同。设计是一门实践性很强的 学科。尽管目前还没有被十分认可的设计学开宗立派 理论, 但众所周知设计是脱胎于传统造物与营造学。 从中华文明发展之始, 其相关知识与理论就与中华人 类社会的发展共同存在。笔者认为, 理论的创新并不 一定非要标新立异, 认祖归宗更为重要。根植传统, 再有所突破是比较适当的研究路径与方法。设计学发 展近二十年以来, 设计理论家的学术背景大部分均基 于传统的历史、文化。尽管具有一定的见地, 但是远 远没有达到理论体系建构层面。究其原因, 主要在于 很多设计实践者虽然有良好的文化底蕴和学术修养,
但是他们不能够在大量实践的基础上，运用宏大的概 念对其理论进行架构。虽然有部分学者提出了一些理 论, 在理论实践的过程中, 最后发现仍然属于经验总 结范畴。很多设计家有志将马克思主义哲学思想运用 到设计实践和理论著述中, 他们认为马克思主义哲学 不在于懂得了客观世界的规律性, 因而能够解释世界, 而在于拿了这种对于客观规律的认识去能动地改造设 计世界。改革开放四十年来, 我国的建筑装饰行业得 到了空前发展, 作为学院派领军人物的清华大学美术 学院张绮曼和郑曙阳两位先生, 在环境设计领域做了 大量的代表性实践项目, 并撰写了重要书籍以飨学人。 如被我们当作设计红宝书的《室内设计资料》和《室 内设计思维与方法》, 其作用与意义影响深远。但是 回到学科理论体系范式上, 不难发现更多的是资料整 理与经验价值, 还没有达到由技入道的水准, 并没有 升华为学科理论思想。

\section{4. 实践与批判}

设计学属于实践性很强的应用型学科, 其高度的 应用性并不代表不需要强大的理论作为支撑并推动创 新。众所周知, 著名的建筑大师均有深厚的文化底蕴 和极强的实践能力, 绝非纸上谈兵。在设计实践时, 不能仅仅从表象进行主观臆断, 并认为大师作品均为 匠作。匠作文化作为当下大力提倡与发扬的工匠精神 得重要组成部分, 但工匠也有自己的哲学思考。从宋、 清等保留下来的《营造法式》、《营造法原》、《营 造则例》中的各种构件材料名称、件数、尺寸、工数、 结构图、具体做法等看, 如果没有坚定的信念, 坚强 的毅力, 严谨的作风, 批判的思维, 难以形成指导中 华历史营造的百科全书，更不会有闻名遐迩的样式雷 存在。通俗地讲, 工匠精神要求工匠在营造实践中不 断的实践、反思、判断、总结。既要考虑单个构件的 形态、尺寸、材性, 还要考虑构件组合之间的关系。 在不同时空环境下的存在状态与审美情思, 循环往复, 渐进式上升为营造思想理论。可以看出, 要想清楚准 确的理解实践与反思的涵义和意义, 必须要对 “实践” “反思” 进行深入思考。运用不破不立, 先分后组的 方式对其进行批判与反思。

《说文》中 “实” 即富也, “践” 即履也。《宋 史・卷四二・理宗本纪二》记载 “真见实践, 深探圣 域, 千载绝学, 始有指归。” “实践”为实践、履行 之意。“反” 即覆也, “思”即容也。“反思”为自 我检讨、反省, 哲学反思更具有高度的自明性。可以 看出, “实践”与 “反思” 作为词汇单独存在时, 其 涵义相对比较固定，但是在不同的语境下，其涵义和 意义则迥然不同。近年来, 随着社会的发展和科学的 进步, 在哲学研究领域, 很多专家也有自己的独到见 解, 并且能够辨证地、客观地、能动地指导大众学习、 工作和生活。如吉林大学孙正聿教授在《哲学通论》 中指出马克思的辨证唯物主义是为人的哲学, 目的在 于让人成为更有价值与意义的人。进而言之, 作为设 
计实践活动主体的人, 就应该坚持以人为本, 不断地 批判与反思, 从而使得设计让生活更美好。

\section{5. 可持续发展观}

在设计实践领域, 何静堂院士在大量设计实践的 基础上, 结合我国建筑与设计行业发展实际情况, 不 断的提出、完善, 进而建立自己的建筑观一一 “两观 三性” 建筑观。通过对何院士近二十年地设计实践经 验总结会发现, “两观三性” 建筑观在中国地域建筑 思想史上有着重要地价值与意义。最为重要地是可持 续发展观是科学发展观的实践化、建筑化, 深化与升 华。

大师之所以能够设计出惊世作品, 主要在于他们 都有自己的设计观和方法论, 并且在在不同程度上与 “两观三性” 有异曲同工之妙。只是何静堂院士将自 己的建筑观阐释得更加全面、综合、高度。比如王小 东院士扎根新疆四十三年, 创作了大量建筑作品, 其 创作观具有一定的动态性和阶段性。在其著作《西部 建筑行脚》中提出了 “重回建筑文化与地域建筑” , 认为建筑文化的实质在于人, 是需要慢工夫才能熏陶 出来的人。 ${ }^{[3]}$ 程泰宁院士在接受《建筑评论》主编金 否访谈时, 强调文化的自觉和自信是任何一个国家建 筑师追求创新的前提。在深入了解中西文化的基础之 上, 要立足自己, 才能实现中国现代建筑的创新。 “立足自己” 不是自我封闭, 而是在全球化的语境下, 对中西文化进行全面深入的比较和思考, 互补共生, 相辅相成, 立足自己、转换提升, 从而实现理论创新 和实践创新。 ${ }^{[4]}$ “建筑的物质形体所蕴涵的过去, 成 为我们的过去, 它是公共的历史, 共有的历史, 是人 类的历史。正因为此, 王澍才在宁波博物馆中对石材 再利用, 以试图恢复 “人们的记忆和精神”。但如前 所述, 这些痕迹也勾勒出未来的使用方式。” ${ }^{[5]}$ 这是 宾夕法尼亚大学教授戴维 - 莱瑟巴罗对王澍建筑与思 想的客观评价。可以看出, 大师们在不同程度和维度 上均具有高度重视可持续发展的共通性, 并且都有着 实践是检验真理的唯一标准地哲思信条。在设计实践 与建造体验中思考, 在思考中实践, 二者相辅相成, 不断升华, 最终形成自己的设计观。

笔者在天山南北和川西高原进行建筑与景观设计 实践时, 同样师承和运用 “两观三性” 建筑观。如在 设计昌吉市中山路街头小游园景观时, 充分考虑项目 所在地为昌吉州州府所在地, 并且该地块是老城, 回 族同胞聚居区。为了尽量尊重场地, 满足公众对原有 场地的记忆和归属感, 最大限度地从形态构成元素、 材质肌理情感、色彩语言意象等方面进行综合把握, 从而使地域性、民族性和文化性达到高度统一。松潘 县在清代属于四川省松潘厅, 是茶马互市重要节点区 域。因地缘优势、历史原因、语言优势等等, 松潘藏 族和丽江纳西族一样, 在茶马古道咽喉位置从事着主 要的商贸活动。改革开放以来, 九寨沟黄龙景区成功 申遗, 旅游业称为阿坝州的重要支柱产业, 当地民众
主要从事与旅游相关的各种商业活动。经过多年地发 展与积累, 松潘藏族同胞在西藏、青海、成都等地都 有很大的产业, 部分行业已达到托拉斯程度。随着生 产方式的改变, 确实带动了一大批人先富起来, 也存 在着部分原生游牧生活方式。基于各种原因, 他们都 喜欢在家乡购置土地, 盖宾馆, 修民宿, 总体投资数 百万到数千万不等。笔者在进行尔让别墅建筑设计时, 从地理文化、汉藏文化、民族文化、宗教文化角度出 发, 对其家庭成员文化背景和职业环境等方面进行综 合分析、比较和判断, 提出 “中西合璧、汉藏和风” 概念, 以 “两观三性” 为理论进行设计实践, 取得了 良好效果。诚然, 可持续发展观既是一种观念, 也是 一种愿景。所有的设计实践均需要有一定的理论指引, 无论大师与否, 均需要理论联系实际, 坚持可持续发 展。

\section{6. 结束语}

综上所述, 社会的发展到了今天的时代, 正确地 认识世界和改造世界地责任, 已经历史地落在当代青 年的肩上。改造自己的认识能力, 改造主观世界同客 观世界的关系。通过实践而发现真理，又通过实践而 证实真理和发展的真理。 ${ }^{[6]}$ 在认识世界和改造世界的 过程中, 肯定会存在诸多矛盾和问题, 但是必须要清 楚地认识到思维与存在、实践与反思、可持续发展观 之间互为因果的辩证关系。要客观地理解思维与存在 的关系; 能动地认知实践与反思的价值意义; 鲜活地 体验可持续发展观对未来社会的永续价值。从而达到 以艺术之剑解哲学之谜, 设计实践服务大众之功效, 更好地将代价与价值进行有机转化, 进而融合再生, 让设计实践更具优秀价值。

\section{致谢}

本文为国家社科基金项目青年项目《城镇化背景 下新疆维吾尔村落民俗文化变迁研究》（14CMZ014）; 教育部人文社科项目青年项目《强本固基下维吾尔族 传统村落景观整治设计研究》（18YJCZH177）; 教育 部人文社科新疆项目《新疆丝绸之路少数民族乡镇景 观规划路径研究》（17XJJC760001）; 教育部产学合 作协同育人项目《高校专业实验室室内装修设计研究》 (项目编号：201702068061, 开来科技（深圳）有限 公司资助）阶段性成果之一。

\section{REFERENCES}

[1] Gao Yiqiang. The Way of Daily Use [M]. Beijing: Xinxing Press, 2018: 7.

[2] Gao Yiqiang. The Way of Daily Use [M]. Beijing: Xinxing Press, 2018: 9. 
[3] Wang Xiaodong. Architectural Construction in the West [M]. Beijing: China Construction Industry Press, 2007: 9 .

[4] Miao Miao. Dialogue with Cheng Taining: Perceive Architectural Design Cultural Confidence with Speculative Thinking [J]. Architecture, 2018 (08): 5254.

[5] David Lisebaro, Shi Yonggao, Hua Zhengyang. The Creative Movement in Wang Xi's Architecture and Thought [J]. Architect, 2013 (01): 15-19.

[6] Mao Zedong. On Practice (phonetic version) [M]. Beijing: Character Reform Press, 1958: 36. 